\section{Estudo \\ Ecidebate}

em Testão

Plamejamento
Revista Estudo \& Debate, Lajeado, v. 26, n. 3, 2019. ISSN 1983-036X

DOI: http://dx.doi.org/10.22410/issn.1983-036X.v26i3a2019.2069

\title{
A EFICIÊNCIA DOS GASTOS EM P\&D NOS GANHOS DE COMPETITIVIDADE INTERNACIONAL: UM ESTUDO PARA PAÍSES SELECIONADOS
}

\author{
Edilson Braga dos Santos ${ }^{1}$, Rodrigo Milano de Lucena ${ }^{2}$
}

\begin{abstract}
Resumo: A busca por competitividade internacional é essencial para um país que queira buscar desenvolvimento no mundo globalizado. Uma das estratégias para atingir esse objetivo é o investimento em pesquisa e desenvolvimento. Diante disso, o objetivo deste trabalho foi calcular a eficiência dos gastos em P\&D de países selecionados para ganhos de competitividade. Os países analisados foram os BRICS (Brasil, Rússia, Índia, China e África do Sul) mais México, Coreia do Sul, Indonésia e Turquia, por apresentarem características econômicas emergentes semelhantes. Como procedimento metodológico foi utilizada a Análise Envoltória de Dados (DEA). A base de dados é composta pelo percentual dos gastos em P\&D em relação ao PIB dos países, disponíveis na base de dados do Banco Mundial, e os sub indicadores relacionados à inovaçáo dentro Global Competitiveness Index, elaborado pelo Fórum Econômico Mundial, para os anos de 2012 e 2016. Os resultados apresentaram que por mais semelhantes que sejam esses países, alguns apresentaram perda de eficiência entre os anos analisados. Não foi encontrada nenhuma tendência ou padrão com relação aos países e sua eficiência, mas o trabalho pode servir de motivação para outras investigaçóes a respeito da eficiência dos gastos em P\&D dos países analisados.
\end{abstract}

Palavras-chave: Gastos em P\&D; Competitividade; Países Emergentes.

\section{EFFICIENCY OF R\&D EXPENSES ON INTERNATIONAL COMPETITIVENESS GAINS: A STUDY FOR SELECTED COUNTRIES}

\begin{abstract}
The search for international competitiveness is essential for a country that wants to seek development in globalized world. One of the strategies to achieve this goal is the investment in research and development. Therefore, the objective of this work is to calculate the efficiency of R \& D spending in selected countries for competitiveness gains. The countries analyzed were BRICS (Brazil, Russia, India, China and South Africa) plus Mexico, South Korea, Indonesia and Turkey, because they had similar economic characteristics. As a methodological procedure, Data Envelopment Analysis (DEA) was used. The database was R \& D expenditures in relation to the countries' GDP, available in the database of the World Bank, and the innovation-related sub-indicators in Global Competitiveness Index by the World Economic Forum, for the years 2012 and 2016. The results showed that, as similar as those countries are, some showed a loss of efficiency between the years
\end{abstract}

1 Acadêmico de Administração da UFMT campus Rondonópolis.

2 Doutorando em Economia/UFF e professor do curso de Administração da UFMT campus Rondonópolis. 
analyzed. No trend has been found with respect to countries and their efficiency, but the work can serve as a motivation for further research into the efficiency of R \& D spending in the countries analyzed.

Keywords: R\&D Expenditures; Competitiveness; Emerging Countries.

\section{Introduçáo}

A inovação tem sido considerada, nos últimos anos, o motor propulsor do crescimento econômico. Segundo Nelson (2006), este é um esquema instigante que na prática, depende ou não de forças em ação fazendo assim surgir um novo ramo básico gerador de inovação e que tende a se estruturar. Nesse contexto, o investimento em P\&D faz toda a diferença e traz uma série de benefícios para quem os executa. Além dos benefícios fiscais, "cedidos" por meio de políticas de incentivo, os investimentos em $\mathrm{P} \& \mathrm{D}$, proporcionam a acumulação de conhecimento e técnicas e sobre esse ponto, é importante que se ressalte que os investimentos em Pesquisa e Desenvolvimento, tem garantido uma maior produtividade a longo prazo, além de ter gerado um "estoque" de conhecimento (NELSON, 2006).

Diante disso, pode-se inferir que a inovação tem garantido a competitividade internacional de algumas economias. A competitividade pode ser entendida como a capacidade de se formular e implementar estratégias competitivas, que permitam à empresa criar, manter e ampliar, de forma duradoura, uma posição sustentável no mercado, embora, alguns fatores devam ser considerados, ou seja, no intuito de se avaliar a capacidade de formular e implementar estratégias, deve-se identificar os fatores que são relevantes para o sucesso competitivo. Estes fatores por sua vez, variam de setor para setor, de acordo com os padróes de concorrência vigentes, verificando sua importância tanto no presente, quanto ao que se pode esperar no futuro, deste modo, a competitividade, no âmbito das empresas, depende da criaçáo e renovaçáo das vantagens competitivas de acordo com cada setor econômico (TAVARES; AFONSO, 2002).

Todavia, é sabido que o desenvolvimento, bem como a competitividade internacional de uma economia podem depender de fatores geográficos, demográficos, acumulaçáo de capital e de tecnologia, por exemplo. Do mesmo modo, sabe-se que também dependem do contexto histórico, do apoio e incentivo do Estado. Nesse sentido, outro fator se torna determinante, as políticas. Arbache (2013) diz que foi por meio de políticas específicas que se deu de forma recente, o grande desenvolvimento industrial e comercial da Coreia do Sul e da China, por exemplo. Para o autor, esse grande desenvolvimento, não teria sido possível sem o protagonismo de suas políticas industriais e comerciais introduzidas e implementadas dentro de um contexto político, social, econômico e institucional específico.

Nas palavras de Carvalho, Serio e Vasconcellos (2012) quando a competitividade é analisada de forma mais ampla, em escala global, outros fatores se tornam intervenientes e até mesmo propulsores, a título de exemplo, os autores dizem que a competitividade está atrelada a fatores culturais, incentivo governamental, que é de extrema importância para desenvolvimento de um país, câmbio, recursos naturais, nível de educação, inovação, tecnologia e outros fatores. Ressalva-se aqui, de acordo com os autores, que a competitividade é vista e analisada como um incentivo econômico advinda da globalizaçáo que gerou a abertura da economia das naçóes. 
É valido ressaltar que investimentos em tecnologia, ciência e inovaçáo têm sido fatores chaves no tocante a competitividade internacional e este é o modelo apreciado e aplicado pelas principais economias mundiais. Nas economias centrais, por exemplo, as indústrias que investem na propriedade intelectual vêm crescendo continuamente, em ritmo mais acelerado do que os demais segmentos, valorizando a máo-de-obra empregada (DALLEMOLE, 2005).

Diante de um cenário competitivo, percebe-se que a inovação desempenha um papel crucial, além de estar intrinsicamente ligado ao sentido atribuído à competitividade, a inovação é um fator que demanda investimentos em $P \& D$, considerando que esta é uma alternativa para expandir, criar e aumentar a participação de mercado.

Portanto, como problema de pesquisa, esse trabalho traz o seguinte questionamento: Qual é a eficiência dos gastos em P\&D para o indicador de competitividade internacional? O Objetivo do trabalho portanto é calcular o indicador de eficiência dos gastos em P\&D para a competitividade internacional dos países.

Assumindo que em um mercado internacional, as disputas não ocorrem apenas entre as empresas, mas sim, entre sistemas produtivos, esquemas institucionais e políticas (SILVA, 2004), os investimentos em Pesquisa e Desenvolvimento tem se tornado cada vez mais necessários para empresas ou naçóes, imersas em um mercado altamente conectado, no tocante a sua performance, capacidade competitiva e principalmente no que diz respeito a sua capacidade de inovação. Sobre isso, é importante salientar que açóes inovadoras são muito dependentes de fontes externas, onde estão inseridas em uma ampla estrutura, a qual facilita alguns processos, modelos e resultados e também dificulta alguns (COSTA; MENEZES; FRANZONI, 2016).

É evidente que a competitividade internacional é uma variável importante para o desenvolvimento dos países. Por isso, o trabalho se torna importante por permitir algumas comparaçōes. Porém, de acordo com o The Global Competitiveness Report publicado pelo Fórum Econômico Mundial (2018), não se pode comparar países muito díspares, visto que isso que pode trazer distorçôes para economias emergentes e náo evidenciar possíveis melhoras nos referidos países. Então, como a gama de países emergentes encontrada na literatura é muito ampla, pretendeu-se criar um agrupamento novo, que apesar de já indicado pelo Fórum Econômico Mundial, não foi objeto de estudos de nenhum trabalho sobre o tema de competitividade, podendo servir de referência para estudos futuros. Tal agrupamento é formado pelos países do BRICS (Brasil, Rússia, Índia, China e África do sul) mais México, Indonésia, Coreia do Sul e Turquia, e foram avaliadas as eficiências dos gastos em P\&D entre os anos de 2012 e 2016.

Para tanto, este trabalho está estruturado da seguinte forma: além desta introdução, são apresentados o referencial teórico que discute conceitos de competitividade e o papel dos investimentos em P\&D para os países emergentes, seguido dos procedimentos metodológicos utilizados e dos resultados encontrados com o método abordado. Por fim, tecem as principais conclusões do trabalho, sua contribuição acadêmica e para políticas públicas. 


\section{Referencial Teórico}

\subsection{Competitividade}

Com a globalização, muitas estruturas mercadológicas e econômicas surgiram e outras se modificaram. Esse processo transformou a estrutura e os horizontes do mercado, de modo que as operaçóes comerciais, tornaram-se de certa maneira, mais em conta, dada as transformaçóes dos sistemas e processos como por exemplo, a redução dos custos de transportes e aquisiçóes de novas tecnologias (NAKANO, 1994), fatores importantes para que economia em desenvolvimento ingressassem ou se inserissem na economia mundial. Para Nakano (1994), a inserção de um país em uma economia mundial gera tensóes entre ajustes nacionais e requisitos de comércio e investimento mundial.

Grandes mudanças na economia mundial são provocadas por circunstâncias críticas. A título de exemplo, tem-se o período pós-guerra que gerou a internacionalização da produção e do comércio nas principais economias do planeta. Portanto, é fácil inferir que para uma expansão de tamanha magnitude, os países devam estar preparados estrategicamente para lidar com a competitividade internacional.

A competitividade é um fator relevante para o desenvolvimento de um país e seu conceito está diretamente ligado à sua capacidade produtiva. Segundo o OECD (1996), em termos conceituais, a competitividade é definida como o grau com que um país produz bens e serviços para um mercado internacional e simultaneamente mantém e aumenta as receitas em seu mercado local. Nesse mesmo sentido, Carvalho, Serio e Vasconcellos (2012), citando estudos realizados pelo Institute for Management of Development (IMD), afirmam que a competitividade é encarada como a capacidade relativa de um país criar e manter ambientes nos quais as empresas podem competir, gerando aumento do nível de prosperidade.

Nessa seara, pode-se incluir o BRICS que vem desempenhando um considerável papel econômico no que tange a competitividade internacional, contudo, essa competitividade apresenta características bem peculiares, dado as especificaçóes e realidade produtiva de cada país pertencente desse grupo.

[...] os países dos BRICS apresentam um padrão de especialização divergente. Por apresentarem abundância em recursos naturais, Brasil, Rússia e África do Sul são mais competitivos em setores com esse tipo de especialização; já Índia e China se especializaram em setores com produção intensiva em trabalho devido à vasta população presente nesses países (SCHMIDT FILHO; LIMA, 2014).

Nesse cenário, em destaque no comercio internacional, tem-se o Brasil com produtos primários agropecuários, a Rússia com produtos primários minerais (petróleo), a Índia com expressiva vantagens em produtos intensivos em recursos naturais e produtos intensivos em trabalho, China, também com produtos intensivos de trabalho e por fim, a África do Sul que também se destaca na produção de produtos primários minerais, incluindo aqui o ouro, diamante e carvão (IPEA, 2010).

É notável a importância do BRICS na economia mundial. Esses países, além de serem ricos quantitativamente no quesito recursos hídricos, minerais e energético, juntos 
correspondem a $43 \%$ da população mundial e um percentual do PIB global equivalente a 23\%, em 2015 (SCHMIDT FILHO; LIMA, 2014; SOARE; SANTOS, 2017).

Com um acentuado crescimento nos últimos anos, o BRICS continua em ascensão em termos de competitividade. De acordo com o site portuguese.people.cn (2017), os países do BRICS configuram uma força importante no desenvolvimento de ciência e tecnologia entre as naçóes em desenvolvimento pois, o relatório de competitividade de 2017 mostrou que os investimentos anual em pesquisa e desenvolvimento destes países correspondem a $17 \%$ do total mundial, com a ressalva de que o mesmo relatório previa ainda, um aumento nos próximos cinco anos para a competitividade dos países do BRICS, com a liderança protagonizada pela China, seguida da Rússia, de acordo com o site. Em 2018, segundo a Folha de São Paulo, a China é o país mais competitivo entre os países do grupo.

Diante disso, percebe-se os impactos dos investimentos em Pesquisa, Desenvolvimento, Ciência e Tecnologia. A obtenção e uso da informação com valor agregado para gerar conhecimento é essencial para o desenvolvimento de novos processos, bens e serviços que, consequentemente, possibilita a inovação e a competitividade das organizaçóes e das nações (ARAÚJO; SILVA; RADOS, 2017).

Schmidt Filho e Lima, (2014) preconizam que em termos de vantagens competitivas, a inovação tecnológica se apresenta como o fator capaz de fornecer o dinamismo necessário às economias que pretendem garantir uma posição de vantagem no comércio internacional. Ou seja, a inovação é a capacidade de gerar produção e deve estar atrelada a geração de valor econômico no mercado, sendo que esta geração tem por locus a empresa, ou seja, a inovação diz respeito à capacidade de se criar novas formas de gerar e apropriar valor no mercado (ARBIX et al. 2010).

\subsection{Países emergentes}

No dinamismo da economia global encontram-se os países emergentes. De acordo com Baumann (2016), há grande diversidade quanto aos países que se enquadram como emergentes. Dentre os agrupamentos, encontra-se o BRICS, que são oficialmente classificados como países emergentes, além de outros grupos tais como o grupo de seis países, formado por Colômbia, Coreia do Sul, Indonésia, México, Polônia e Turquia (BAUMANN, 2016). Para fins dos objetivo este trabalho, o foco será voltado além do BRICS, México, Turquia, Indonésia e Coreia do Sul, por serem países emergentes e possuírem ambientes econômicos aproximados.

Segundo Pimenta (2013), conceitualmente, há teorias não-conclusivas quanto à "países emergentes" já que para o autor há muitas assimetrias sustentadas inclusive entre os BRICS por exemplo, por não haver uniformidade de regime político, de inserção econômica internacional, de condiçóes socioeconômicas e de perspectivas securitárias. Contudo, o autor sumariza que um país emergente tem forte identidade internacional, baseada na compreensão interna da posição do país no sistema internacional, além de estar situado em um contexto estrutural diferente daqueles das economias industrializadas, mas com capacidades materiais que permitiriam influenciar a economia global, assim, países 
emergentes, envolvem-se com tópicos da agenda internacional, além de adotarem estratégias de ação reformistas e serem também potências regionais.

Historicamente, a inserção dos países emergentes, de forma competitiva na economia mundial, foi um processo atrasado, considerando que foi apenas em meados da década de 1970 e começo da década de 1980 que empresas de países em desenvolvimento passaram a expandir suas operaçóes para o mercado internacional de forma reativa (REIS-CARDOSO, 2010).

Citando Lall (1980), Reis-Cardoso (2010) reporta que a inserção de empresas de países emergentes no mercado internacional, tem como principal causa a rápida mudança tecnológica que se verificou nesses países. Segundo o autor, os países em desenvolvimento tornaram-se capazes de criar e transferir para o exterior considerável quantidade de tecnologias industriais, contribuindo assim para o desenvolvimento de uma nova ordem econômica global, onde há uma reorganização do papel das naçôes emergentes no âmbito internacional.

Com a inserção de economias emergentes no mercado internacional, houve uma mudança no ritmo da economia global, por serem economias que apresentam altos potenciais tecnológicos e em questóes associadas às demanda externa por seus bens e serviços, que é um dos importantes canais de interação com as economias avançadas, tanto pela perspectiva de geração de oportunidades de negócios quanto, internamente, enquanto fonte de progresso técnico que pode ser absorvido. (BAUMANN, 2016).

Nesse processo, um fator se torna igualmente importante, os incentivos que esses países recebem à internacionalização de suas economias. Contudo a UNCTAD (UNITED NATIONS CONFERENCE ON TRADE AND DEVELOPMENT, 2006), salienta que para a expansão, além das fronteiras das áreas de atuação das empresas, os países com baixa renda devem primeiro focar no estabelecimento de um ambiente competitivo e favorável ao desenvolvimento e fortalecimento das firmas, e só depois prover os incentivos necessários.

Embora os incentivos governamentais estejam crescendo no tocante ao estímulo da internacionalização de empresas, muitas falhas ainda existem nesse processo. Segundo Reis-Cardoso (2016), os estímulos devem servir para compensar de certa forma, a natural desvantagem competitiva dessas empresas, devem sobretudo apoiar, promover e acima de tudo estimular a inovação da indústria doméstica também. E quanto a isso, na visão do autor, há claramente uma lacuna em relação a políticas institucionais que respondam de forma efetiva.

Os incentivos governamentais, podem vir de várias maneiras, entre elas os incentivos fiscais, e aqui se inclui todos os tributos e impostos. Outra forma de incentivo, seria as políticas públicas voltadas a P\&D, segundo Reis-Cardoso (2010), políticas e incentivos voltados a Pesquisa e Desenvolvimento são, além de importante, necessários por assegurarem um mercado de trabalho altamente qualificado e dinâmico, e aumentar a capacidade de inovação.

Os países emergentes apresentam capacidade tecnológica frente a competitividade internacional, sua ascensão é amplamente notável, a exemplo do grupo BRICS, porém, outro grupo de países tem chamado a atenção de economistas e estudiosos, o bloco formado 
por México, Indonésia, Coreia do Sul e Turquia, ou simplesmente MIST. Para Bertão e Costa (2012), o que tem chamado a atenção para esses países, é o fato de eles crescerem mais, por terem passado por "turbulências" econômicas menos profundas nos últimos anos e por serem menos burocráticos. Ressalta-se aqui que os mesmos fazem parte de onze economias promissoras, apontadas por O’Niell.

Com performance promissora, a expansão econômica do MIST é inegável. Para Bertão e Costa (2012), os países do MIST estão ganhando visibilidade por causa da desaceleração dos BRICS. Em um quadro comparativo entre BRICS e MIST, os autores mostram que em relação ao PIB de 2012, a realidade configurava 4,86\% dos BRICS contra $4 \%$ do MIST. Ou seja, uma diferença relativamente baixa entre os grupos, levando em conta a composição dos mesmos.

De acordo com Bertão e Costa (2012), por um lado, o México se beneficia com uma certa dependência econômica de seu vizinho Estados Unidos, porém a maior vantagem para a economia mexicana, foi a conjuntura econômica chinesa, principalmente pela valorizaçáo do yuan e aumento dos custos em direitos trabalhistas, além do fácil acesso ao mercado interno dos EUA.

Quanto a Turquia, uma de suas principais vantagens, diz respeito a proximidade territorial com a Europa, colocando a em posição estratégica para um forte relacionamento econômico com este mercado, ao passo que a Indonésia, em 2012, contava principalmente com uma população jovem e os avanços da democracia melhorando as expectativas de estabilidade política no longo prazo, o que segundo especialistas econômicos, fatores essenciais que formam a base para altas taxas de elevação do PIB nas próximas décadas (BERTÃO E COSTA, 2012).

Já a Coreia do Sul, seu ponto focal é a expansão pautada na qualidade, Segundo Bertâo e Costa (2012), a riqueza e a altíssima qualidade profissional dos sul-coreanos sáo características marcantes do país, sendo este um dos principais mercados da Ásia. Os autores chamam atenção também para a concentração de gastos (investimentos) em educação, sendo este o maior do país e um dos maiores do mundo.

\subsection{BRICS e Investimentos em P\&D}

As principais mudanças estruturais nas grandes economias estão de alguma forma ligadas à investimentos em inovação e tecnologia, e são esses fatores que tem garantido, nos últimos anos, maior notoriedade aos países que compóem o BRICS (FERREIRA; CARVALHO, 2010).

Tamanha é a força dessa união que há evidencias em diversos estudos de que o BRICS, em termos de renda per capita, crescimento do Produto Interno Bruto e movimentação financeira, pode se tornar a maior potência econômica mundial nos próximos cinquenta anos (VIEIRA; VERÍSSIMO, 2009; FERREIRA; CARVALHO, 2010). É claro, que o crescimento desses países se dá de maneiras desigual, de acordo com as particularidades de cada um e com fatores tanto constitucionais quanto políticos.

O BRICS transcende as limitaçóes de uma sigla, sendo indiscutivelmente uma potencial e promissora entidade político-diplomática de países em ascensão, conforme o 
Ministério das Relações Exteriores (2015). Esses países estão entre os maiores em termos de extensão geográfica e demográficas, além de apresentarem uma preponderância regional, aspiraçáo por um papel global, e pelo questionamento da hegemonia norte-americana na ordem mundial (CAVALCANTI et al., 2011). A seguir, ilustra-se de maneira sintética, os principais pontos em comum e as principais diferenças entre os países que formam o BRICS de acordo com Cavalcanti et al. (2011).

Quadro 1: Principais pontos em comum e diferenças entre os BRICS

\begin{tabular}{|c|c|}
\hline Principais Pontos em Comum & Principais Diferenças \\
\hline $\begin{array}{l}\text { - Disposição de recursos de poder militar, político e } \\
\text { econômico; } \\
\text { - Capacidade de contribuir para a gestão da ordem } \\
\text { internacional em termos regionais ou globais; } \\
\text { - Níveis de crescimento econômicos atrativos; } \\
\text { - Crença em seu direito a um papel mais influente } \\
\text { de relaçốes entre si; } \\
\text { - Náo estâo intimamente integrados em um sistema } \\
\text { de alianças com os EUA. }\end{array}$ & $\begin{array}{l}\text { - Poder e importância geopolítica; } \\
\text { - Graus de integraçáo à economia } \\
\text { global; } \\
\text { - Trajetórias históricas e contextos } \\
\text { culturais distintos; } \\
\text { - Sistemas políticos domésticos }\end{array}$ \\
\hline
\end{tabular}

Fonte: adaptado de Hurrell (2009)

Além das características já elencadas, é importante que se conheça suas principais características no tocante a seus aspectos e estruturas econômicas, sociais e étnico-cultural, assim no que se refere aos aspectos econômicos, Fedato, Pires e Trez (2017), dizem que estes países apresentam grande potenciais, contudo, com algumas deficiências, a título de exemplo, os autores afirmam que a Índia tem influências negativas sobre a modernização das empresas, levando em conta o volume de capital disponível para investimento, por ainda haver muitas empresas de capital fechado nesse país. Oposto a essa realidade, na China há um grande número de empresas de capital aberto, porém controladas pelo Estado, o que acarreta em interferência política, característica institucional, igualmente presente nos outros países que compóem o BRICS (FEDATO, PIRES E TREZ, 2017).

Ainda segundo os autores, a presença frequente de empresas estatais nos mercados emergentes afeta as economias desses países, em termos de limitações a inovação, além de ser comum a prática de suborno, que tem aumentado em média 5\% o custo dos negócios para as empresas e isso atribui uma fragilidade às instituições formais presente no BRICS, obrigando as a se destacarem pela sua credibilidade.

Nos aspectos sociais, o grande destaque está no fato de uma boa parte dos consumidores desses países buscarem produtos e serviços de baixo custo, porém, levando em conta que outra parcela desses consumidores, presentes nos segmentos global, tem atingido a educação superior (FEDATO, PIRES E TREZ, 2017). Os autores destacam ainda que os consumidores têm despertado um olhar atento à questóes ambientais e de sustentabilidade.

Por fim, Fedato, Pires e Trez (2017), trazem os fatores étnicos-culturais, com destaque para a mudança na mentalidade sobre o desenvolvimento de novos produtos e serviços, alertando sobre ser comum nesses países, a troca de favores para se obter vantagens 
para atingir os objetivos empresariais, além de ser comum também, fraudes no mercado financeiro devido à falta de mecanismos de transparências.

Dado esses conceitos e características iniciais do BRICS, outros pontos se destacam entre esses países, dentre eles os investimentos em Pesquisa e Desenvolvimento, Gameiro e Gameiro (2006, p. 4) afirmam que "durante décadas, vários países em desenvolvimento melhoraram seu nível de educação e a capacidade de inovação, tornando-os potenciais receptores das atividades de $\mathrm{P} \& \mathrm{D}$, além de aumentarem seus investimentos em $\mathrm{P} \& \mathrm{D}$, em proporção ao Produto Interno Bruto (PIB)".

Diversas correntes do pensamento econômico reforçam que investimento em $\mathrm{P} \& \mathrm{D}$ é crucial para o desenvolvimento industrial, uma vez que proporciona maior eficiência no processo produtivo e maior competitividade para as empresas e isso se reflete em inovação tecnológica, sendo esta a grande ferramenta para o crescimento econômico e para os ganhos de eficiência e de competitividade (MARTINS et al. 2016).

$\mathrm{O}$ agrupamento formado pelo BRICS é uma das principais referências quando o assunto é liderança em tecnologia e inovação científica nos países emergentes, facilmente compreensível considerando que este bloco tem investido mais em Pesquisa e Desenvolvimento, logo, esses investimentos tem assegurando assim a inovação e consequentemente a competitividade econômica dos mesmos. Segundo Fernandes et al. (2012), os investimentos do BRICS em P\&D vem crescendo ao longo da década de 2000, porém ainda se percebe algumas desigualdades quando se trata de registros de patentes industriais, fenômeno que vem crescendo entre os BRICS, principalmente na China (FERNANDES et al. 2012).

Observa-se a importância para os BRICS na incorporação da Pesquisa e Desenvolvimento e Inovação, não apenas para seu crescimento econômico, mas sobretudo para sua evolução qualitativa, além de que na atual fase da sociedade do conhecimento, a inovação se torna um dos principais impulsores do desenvolvimento econômico, implicando também maior poder político (FERNANDES et al. 2012).

\section{Procedimentos Metodológicos}

Estudos de eficiência permitem a avaliação de agentes baseados nos princípios microeconômicos do mainstream, como a maximização de lucro. Três medidas de eficiências podem ser aplicadas: eficiência técnica, eficiência em escala, e eficiência alocativa.

$\mathrm{O}$ conceito de eficiência pode incluir a orientação a input ou a orientação a output. Num modelo orientado a input, a DMU (Decision Making Unit) ganhará eficiência mantendo os atuais níveis de output, diminuindo os inputs. Nesse caso, cada país da amostra representa uma DMU. Técnicas para medir a eficiência requerem estimação de uma fronteira de produção em que a performance do agente possa ser avaliada. Dois conjuntos de técnicas, paramétricas e não-paramétricas, estão disponíveis para a determinação das fronteiras estocásticas ou determinísticas. O DEA é uma técnica não-paramétrica que usa programação linear para mensurar a eficiência relativa dos agentes.

Comparada com a regressão ou com o método analítico de fronteira estocástica, o DEA mostra algumas vantagens. Primeiramente, o DEA permite a manipulação de 
múltiplos inputs e outputs. Em segundo lugar, o DEA não requer o pressuposto sobre específicas formas funcionais que ligam inputs e outputs. Por outro lado, os resultados do DEA podem ser afetados por limitaçóes bem conhecidas tais como a influência de dados externos, o ambiente determinístico e a sensibilidade para o erro de medição.

Pela escolha dos países envolvidos na pesquisa, presume-se que as DMU preenchem as três condições básicas necessárias para a homogeneidade: as DMUs são envolvidas no mesmo processo, as mesmas medidas de eficiência são aplicadas a todas as DMUs, e todas as DMUs estão operando sobre as mesmas condições. Com isso, as DMUs atendem aos pressupostos de homogeneidade de Dyson et al. (2001), já que se referem a atividades muito próximas (os gastos em $\mathrm{P} \& \mathrm{D}$ ) produzindo produtos comparáveis (aumento da competitividade), com as mesmas características.

No caso de DEA com dados dispostos em painel, ou seja, várias observaçôes para os países em vários anos, é necessário utilizar uma combinação de modelos para verificar as eficiências para esse tipo de dado.

O problema da eficiência dos gastos em P\&D dos países entre os dois anos (2012 e 2016), são representados pelo seguinte cálculo:

$$
d_{p}^{t}\left(q_{i s}, x_{i s}\right)^{-1}=\left\{\begin{array}{c}
\operatorname{Max}: \theta \\
(\theta, \lambda) \\
\text { s.t. }: \bar{x}_{i s}-X_{t} \bar{\lambda} \geq \overline{0} \\
\\
Q_{t} \bar{\lambda}-\theta \bar{q}_{i s} \geq \overline{0} \\
\bar{e} \bar{\lambda}=1 \\
\bar{\lambda} \geq \overline{0}
\end{array}\right.
$$

Nesse caso, $d_{p}^{t}\left(q_{i s}, x_{i s}\right)^{-1}$ significa o esquema produtivo de um país (DMU) i no período $s$ (2012), expresso por $\left(q_{i s}, x_{i s}\right)$, avaliado pela ótica do produto, com rendimentos variáveis a escala, e utilizando-se como referência os países do período $t$ (2016). A exponenciação -1 serve apenas para expressar os valores inversos, a fim de facilitar a interpretação. Para retornos constantes a escala, tem-se a seguinte equaçáo:

$$
d_{p}^{* t}\left(q_{i s}, x_{i s}\right)^{-1}=\left\{\begin{array}{c}
\operatorname{Max}: \theta \\
(\theta, \lambda) \\
\text { s.t. }: \bar{x}_{i s}-X_{t} \bar{\lambda} \geq \overline{0} \\
Q_{t} \bar{\lambda}-\theta \bar{q}_{i s} \geq \overline{0} \\
\bar{\lambda} \geq \overline{0}
\end{array}\right.
$$

A partir dessas duas equações, são realizadas diversas combinaçôes para verificar a decomposição da produtividade total dos fatores analisados. No caso do fator multiplicativo da mudança de produtividade causado exclusivamente por variaçôes de eficiência técnica é técnica, é dado por $m e t_{p}^{s, t}$ na equação que segue:

$$
\operatorname{met}_{p}^{s, t}\left(x_{s}, q_{s}, x_{t}, q_{t}\right)=\frac{d_{p}^{t}\left(x_{t}, q_{t}\right)}{d_{p}^{s}\left(x_{s}, q_{s}\right)}
$$


O caso da variação de tecnologia é calculado pelo índice Malmquist para modificações de tecnologia dado por:

$$
m t_{p}^{s, t}\left(x_{s}, q_{s}, x_{t}, q_{t}\right)=\sqrt{\frac{d_{p}^{s}\left(x_{s}, q_{s}\right)}{d_{p}^{t}\left(x_{s}, q_{s}\right)} \frac{d_{p}^{s}\left(x_{t}, q_{t}\right)}{d_{p}^{t}\left(x_{t}, q_{t}\right)}}
$$

O que a equação indica é que para verificar as alterações de tecnologia, deve-se calcular DEAs com as tecnologias do período existente e compará-las com as tecnologias do período posterior.

Uma mudança na escala de escala é suficiente para alterar a produtividade da DMU sem que haja alteraçóes nas outras dimensóes da produtividade. Portanto, é importante calcular o efeito da modificação de escala sobre a produtividade através da equação:

$$
\operatorname{mee}_{p}^{s, t}\left(x_{s}, q_{s}, x_{t}, q_{t}\right)=\sqrt{\frac{d_{s}^{*}\left(x_{t}, q_{t}\right)}{d_{s}\left(x_{t}, q_{t}\right)} \frac{d_{s}\left(x_{s}, q_{t}\right)}{d_{s}^{*}\left(x_{s}, q_{t}\right)} \frac{d_{t}^{*}\left(x_{t}, q_{t}\right)}{d_{t}\left(x_{t}, q_{s}\right)} \frac{d_{t}\left(x_{s}, q_{s}\right)}{d_{t}^{*}\left(x_{s}, q_{s}\right)}}
$$

O último fator que participa da variação da produtividade total é a variação das economias de escopo. As composiçóes de insumo e produto podem variar no tempo, afetando sua produtividade. A equação para capturar o quanto a produtividade das DMUs variou em função das modificações das economias de escopo é dada por:

$$
\operatorname{meesc}_{p}^{s, t}=\sqrt{\frac{d_{s}^{*}\left(x_{s}, q_{t}\right)}{d_{s}\left(x_{s}, q_{t}\right)} \frac{d_{s}\left(x_{s}, q_{s}\right)}{d_{s}^{*}\left(x_{s}, q_{s}\right)} \frac{d_{t}^{*}\left(x_{t}, q_{t}\right)}{d_{t}\left(x_{t}, q_{t}\right)} \frac{d_{t}\left(x_{t}, q_{s}\right)}{d_{t}^{*}\left(x_{t}, q_{s}\right)}}
$$

Diante disso, as modificações na produtividade total das DMU (países) são calculadas com o produto de todos os fatores decompostos de produtividade, dado por:

$$
m p t_{p}^{s, t}=\operatorname{met}_{p}^{s, t} \chi m t_{p}^{s, t} \chi m e e_{p}^{s, t} \chi \operatorname{meesc} c_{p}^{s, t}
$$

Com DEA só se pode utilizar dois períodos por vez. Então, um painel de dados típico para a utilização com a metodologia DEA consiste em um conjunto de observaçóes referentes a n DMUs, nos períodos s (anterior) e $\mathrm{t}$ (posterior), embora mais períodos possam ser utilizados, dois a dois, em várias rodadas. No caso do presente estudo, apesar de os pesquisadores possuírem informaçóes ano a ano dentro do intervalo da amostra, os anos utilizados para a análise foram o de 2012 e 2016 por representar o intervalo de tempo mínimo para mensurar uma possível mudança estrutural nos países objetos do estudo (CARVALHO; KUPFER, 2011). Para que a utilização do painel DEA possa decompor as fontes de modificação da produtividade das DMUs, é necessário que se possam avaliar os esquemas produtivos de um período em relação à tecnologia existente em outro período.

Apesar de algumas limitaçóes, diversos trabalhos internacionais apresentam a relevância do método para avaliar a eficiência do gasto em P\&D. Tais trabalhos seguem na tabela abaixo: 
Tabela 1 - Trabalhos internacionais que apresentam a relevância do método para avaliar a eficiência do gasto em P\&D

\begin{tabular}{|c|c|c|}
\hline Autor & Input & Output \\
\hline Wu et al. (2019) & $\begin{array}{l}\text { - Ativos totais } \\
\text { - Número de empregados } \\
\text {. Gastos em P\&D }\end{array}$ & $\begin{array}{l}\text { - Retorno do Ativo (ROA) } \\
\text { - Lucro por ação } \\
\text {. Número de patentes }\end{array}$ \\
\hline $\begin{array}{l}\text { Liu, Lu, Cheng } \\
\text { (2018) }\end{array}$ & $\begin{array}{l}\text { Empresas de P\&D Nacional } \\
\text { - Empresas de P\&D extrangeiro } \\
\text {. Pessoal envolvido em P\&D }\end{array}$ & $\begin{array}{l}\text { - Patentes } \\
\text { - Artigos científicos }\end{array}$ \\
\hline $\begin{array}{l}\text { Dobrzanski } \\
(2018)\end{array}$ & $\begin{array}{l}\text { Publicaçóes anuais } \\
\text { - Gasto Privado em P\&D( em \% } \\
\text { do PIB) }\end{array}$ & $\begin{array}{l}\text { - Número de patentes } \\
\text { - Produção de produtos de alta } \\
\text { intensidade tecnológica }\end{array}$ \\
\hline $\begin{array}{l}\text { Bielicki e } \\
\text { Lesniak (2016) }\end{array}$ & $\begin{array}{l}\text { Fundos europeus (fundo } \\
\text { social europeu, fundo de } \\
\text { coesão, fundo europeu de } \\
\text { desenvolvimento regional) } \\
\text {. Contribuição nacional }\end{array}$ & $\begin{array}{l}\text { - Participação da exportação dos produtos } \\
\text { de alta intensidade tecnológica no total } \\
\text { das exportaçóes } \\
\text { - Participaçáo do pessoal ocupado em } \\
\text { P\&D no total de empregos } \\
\text { - Pedidos de patentes no escritório } \\
\text { europeu por milhóes de habitantes }\end{array}$ \\
\hline
\end{tabular}

\subsection{Dados}

Os dados foram retirados dos indicadores do Global Competitiveness Index (GCI) apresentados anualmente pelo Fórum Econômico Mundial, cobrindo 137 países e mede a competitividade nacional de cada país, definida pelos conjuntos institucionais, políticas e fatores que determinam o nível de produtividade. O presente trabalho utilizou os indicadores que estão relacionados com inovação (pilar $12 \mathrm{com} 7$ sub índices).

A fim de comparar de forma eficiente, o relatório GCI elaborado pelo Fórum Econômico Mundial faz algumas classificaçóes de países, para que o índice de competitividade possa ser comparado, como por exemplo os países da zona do Euro. Neste trabalho, foi criado um conjunto novo de países emergentes ainda não existente no referido relatório, que de acordo com a literatura, são países similares, que buscam desenvolvimento, e que podem ser comparados por possuírem realidades socioeconômicas próximas. O grupo criado então engloba os países do BRICS (Brasil, Rússia, China, Índia, e África do Sul) mais México, Indonésia, Coreia do Sul e Turquia.

Os dados do input do modelo (os gastos em P\&D) foram extraídos na consulta à base de dados do Banco Mundial, para os anos de 2012 a 2016. De acordo com o World Bank Database estes dados se referem a gastos domésticos brutos em Pesquisa e Desenvolvimento, expressos como porcentagem do PIB, para cada país e para cada ano analisado. Estes valores incluem capital e despesas correntes nos quatro principais setores:

3 Disponível em https://data.worldbank.org 
empresa, governo, educação superior e empresas sem fins lucrativos. Os gastos em $\mathrm{P} \& \mathrm{D}$ abrangem pesquisa básica, pesquisa aplicada e desenvolvimento experimental. Todos os dados foram mensurados pelo Instituto de Estatística da UNESCO e disponibilizados no site do Banco Mundial. Os pesquisadores então aplicaram filtros para coletar tal informação dos países da amostra exportados em arquivo Excel e que foram compatibilizados pelos softwares estatísticos utilizados para a pesquisa.

Pela metodologia DEA em painel permitir cálculos apenas entre dois períodos, os dados utilizados foram os anos de 2012 e 2016, a fim de identificar mudanças na produtividade nesse período. O software utilizado foi o $\mathrm{R}$, juntamente com os pacotes Benchmarking, frontier e plm.

\section{Apresentaçáo dos Resultados}

Dada a importância que a inovação tem para ganhos de competitividade internacional entre os países, segue na figura abaixo a evolução dos gastos em P\&D, expressos em porcentagem do PIB, entre os períodos analisados nesse trabalho:

Figura 1: Gastos em P\&D com relação ao PIB dos países selecionados (em termos relativos)

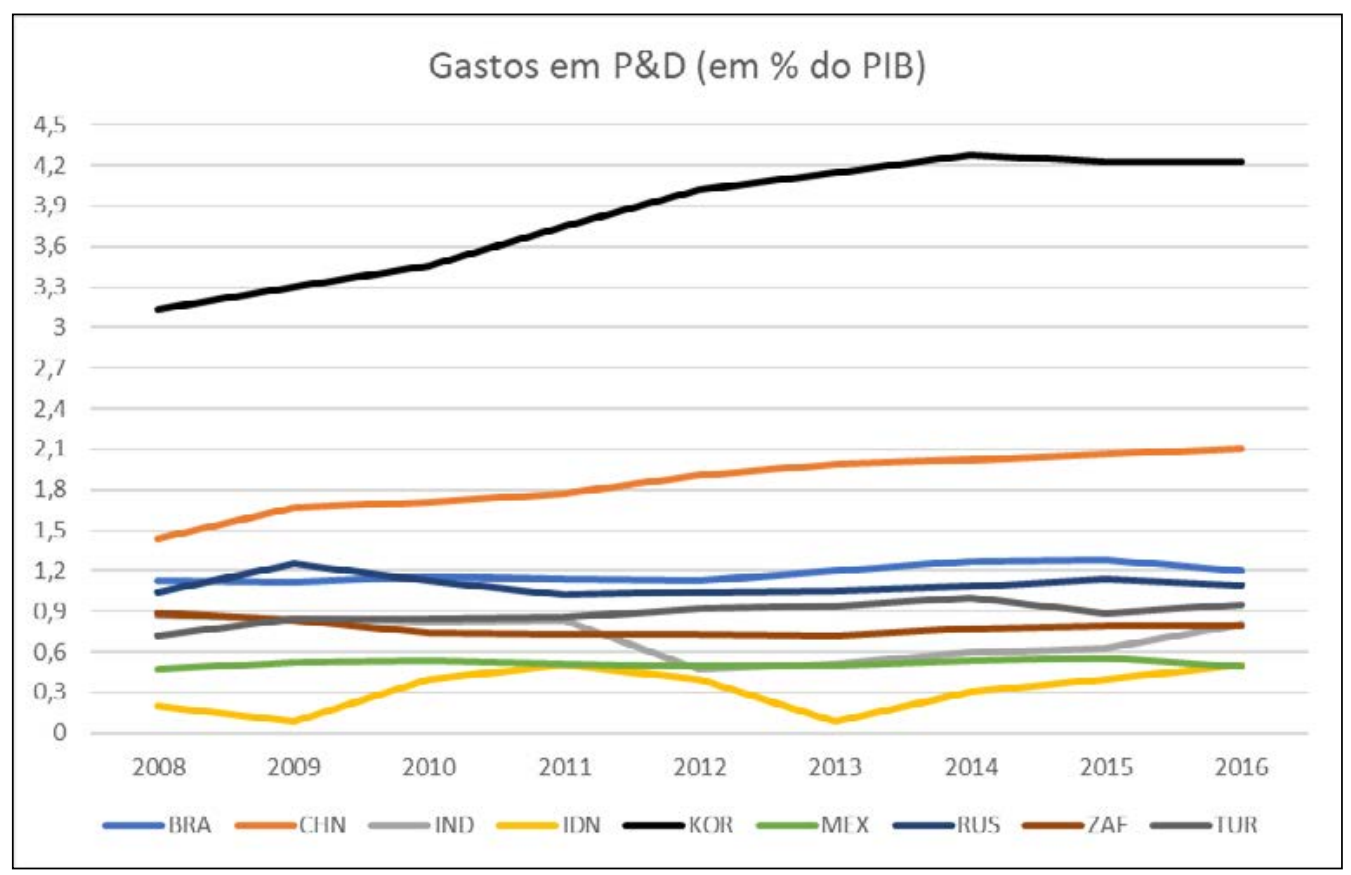

Fonte: Elaborado pelos autores com dados do Banco Mundial (2018)

O gráfico chama a atenção para evidências importantes. No período que vai de 2008 (ano de início da maior crise econômica internacional) a 2016, quase todos os países possuem uma tendência de estabilização dos gastos em $\mathrm{P} \& \mathrm{D}$, com exceção da Indonésia, que oscilou bastante o montante de gastos em $P \& D$ durante o período analisado. Alguns países responderam diferentemente aos impactos da crise como a Coreia do Sul, que 
vinha investindo pesado em educação e tecnologia desde a década de 1960, e continuou a aumentar os gastos em P\&D mesmo após a crise internacional. Atentando a isso, a Coreia do Sul é um dos países que mais investem em pesquisa e desenvolvimento do mundo, e seu gasto relativo é, em média, o dobro do resto dos países objetos desta análise, e sob forte apoio do Estado, conseguiu unir esforços de educação, pesquisa e desenvolvimento a aplicá-los no desenvolvimento industrial principalmente a partir do período pós-guerra (CHANG, 1993).

A China também merece destaque já que mesmo após a crise, continuou a tendência de aumento e estabilização dos gastos em P\&D. Esses fatos estão de acordo com as afirmaçóes de Fernandes et al. (2012), onde diz que os países dos BRICS vêm aumentando seus investimentos em pesquisa, desenvolvimento e inovação desde o ano 2000.

Por serem apresentados dados relativos (o montante de gastos em P\&D em relação ao PIB do país), aqui não se mede a redução dos gastos absolutos. Em todos os países analisados, houve redução de gastos em termos absolutos, pelo menos nos três anos seguintes à crise de 2008 mas, concomitante a isso, houve também queda no PIB dos países, o que ratifica a escolha do artigo por se trabalhar com termos relativos e não absolutos.

Apesar de Pimenta (2013), argumentar que há assimetrias socioeconômicas e de inserção no comércio internacional que podem desclassificar um possível agrupamento, a evolução dos gastos em P\&D de alguns países pertencentes ao BRICS são bem semelhantes, tais como Brasil e Rússia, por exemplo. No agrupamento objeto deste estudo, encontra-se também semelhanças entre os gastos do México e da Indonésia, e entre a África do Sul e a Turquia.

Com relação a competitividade dos países, a Figura 2, abaixo, mostra a evolução do índice de competitividade geral, construído com uma gama de informaçóes a respeito dos países, tais como ambiente institucional, tributação, ambiente de negócios, burocracia, qualificação da mão de obra, inovação, dentre outros. 
Figura 2: Evolução do Global Competitiveness Index para os países selecionados

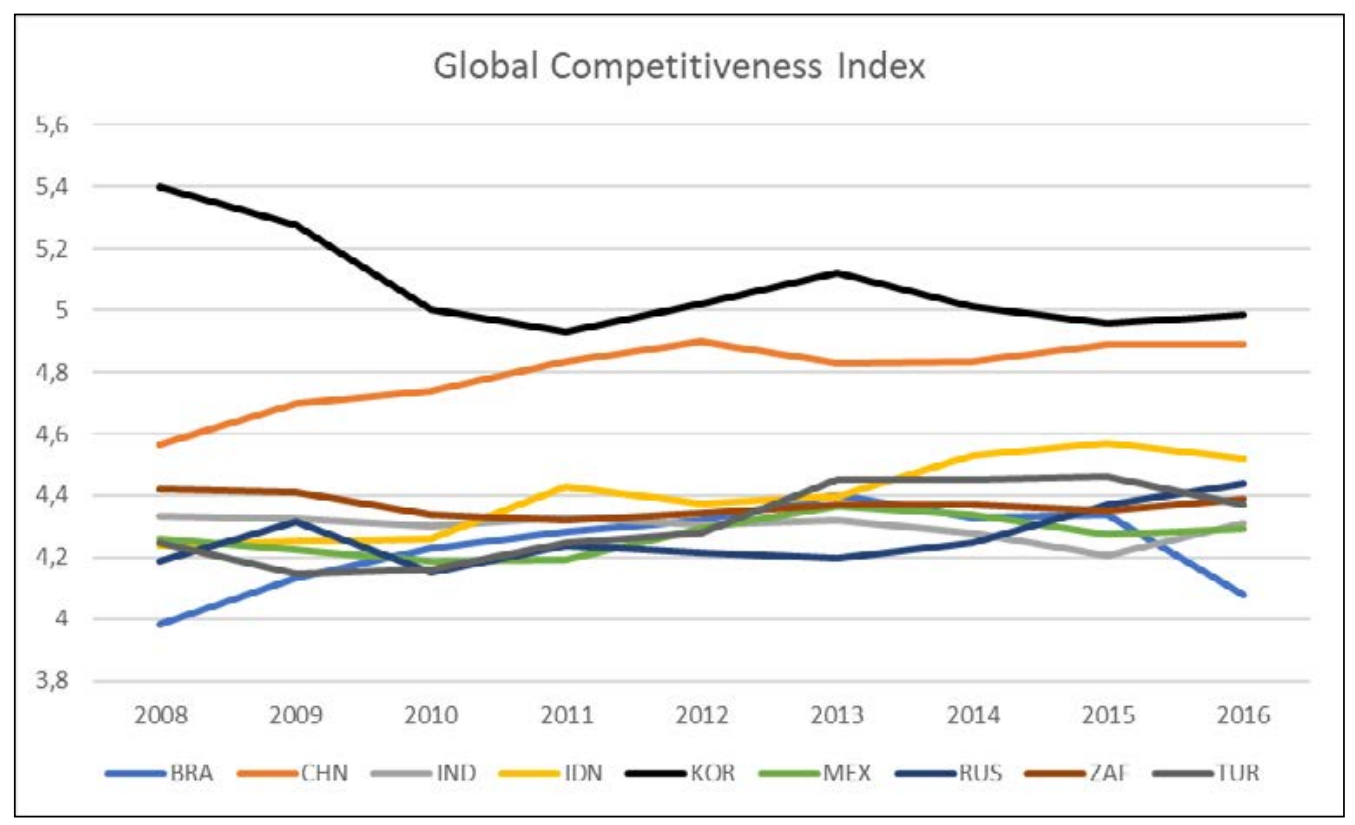

Fonte: Elaborado pelos autores com base nos dados do Fórum Econômico Mundial (2018)

Pode-se observar que o histórico dos resultados do índice reforça que a escolha do agrupamento dos países foi boa visto que no que se refere a competitividade internacional, os desempenhos desses países são bem próximos. Primeiramente, observa-se que o país que mais gasta em $P \& D$ do grupo, é o país que apresenta o maior índice de competitividade durante o período analisado. Esse fato já pode dar indícios de que a competitividade de um país está relacionada com o total de investimentos em $P \& D$, porém, o objetivo do trabalho é analisar a eficiência desses gastos. Portanto, como observado na Figura 1, comparado com a Figura 2, não parece que o alto gasto em $P \& D$ da Coreia do Sul é eficiente visto que seu índice de competitividade não é muito maior que os demais países da amostra. Claro que, como discutido no referencial, há outras variáveis que podem determinar a competitividade dos países, mas ignorando demais variáveis pode-se pressupor que os gastos em P\&D na Coreia do Sul não são eficientes para ganhos de competitividade.

Diante disso, a China, que apresenta gastos em P\&D por volta de metade dos gastos da Coreia, em termos relativos, apresentou índices de competitividade muito próximos aos da Coreia, indicando assim ser mais eficiente. Portanto, nẫo se pode afirmar que países que mais gastam em pesquisa e desenvolvimento serão mais competitivos internacionalmente.

Graficamente, apesar dos gastos variarem um pouco entre os outros países, com relação ao índice de competitividade, os demais países se apresentam tecnicamente na mesma situação. Vale destacar que o índice possui nota máxima de 7 pontos. O país melhor avaliado no ano de 2017 foi a Suíça com GCI de 5,87 e o país que possui o menor índice de competitividade é o lêmen com 2,87 (GCI, 2018). 
Mesmo com o argumento de Schmidt Filho e Lima, (2014) de que os BRICS vêm ganhando espaço na competitividade internacional, corroborado por Cavalcanti et al. (2011), que apresenta o potencial do grupo para os próximos 50 anos baseado nas características sobre extensão territorial, tamanho do mercado consumidor e disponibilidade de recursos naturais, o que se apresentou entre os índices de competitividade foi uma estagnação entre os anos da amostra, indicando que, para ganhos de competitividade, os referidos países ainda têm um longo caminho a percorrer, quando comparado ao cenário internacional.

Após a aplicação da metodologia escolhida, a chamada Análise Envoltória de Dados (DEA), chegam-se a alguns resultados que permitem chegar a algumas conclusóes a respeito do objetivo do trabalho. A Tabela 2, abaixo apresenta os resultados do cálculo da Análise Envoltória de Dados (DEA) para os países selecionados (DMU) entre os anos de 2012 e 2016.

Tabela 2: Resultados do DEA para os países selecionados

\begin{tabular}{c|c|c|c|c|c|c|c|c|c}
\hline DMU & $\begin{array}{c}\text { \%GP\&D/ } \\
\text { PIB (2012) }\end{array}$ & $\begin{array}{c}\text { GCI } \\
\mathbf{( 2 0 1 2 )}\end{array}$ & $\begin{array}{c}\text { \%GP\&D/ } \\
\text { PIB (2016) }\end{array}$ & $\begin{array}{c}\text { GCI } \\
(\mathbf{2 0 1 6})\end{array}$ & MPT & MET & MT & MEE & MEESC \\
\hline Brasil & 1,13 & 4,40 & 1,20 & 4,06 & 1,61 & 1,00 & 1,09 & 1,46 & 1,01 \\
\hline China & 1,90 & 4,83 & 2,10 & 4,95 & 1,78 & 1,00 & 1,01 & 1,41 & 1,25 \\
\hline Índia & 0,47 & 4,32 & 0,80 & 4,52 & 0,46 & 1,01 & 1,05 & 0,44 & 0,98 \\
\hline Indonésia & 0,40 & 4,40 & 0,50 & 4,52 & 0,86 & 1,00 & 1,12 & 0,88 & 0,87 \\
\hline $\begin{array}{c}\text { Coreia do } \\
\text { Sul }\end{array}$ & 4,02 & 5,12 & 4,22 & 5,03 & 1,08 & 1,00 & 1,15 & 0,78 & 1,21 \\
\hline México & 0,50 & 4,36 & 0,49 & 4,41 & 0,94 & 1,00 & 1,10 & 0,80 & 1,08 \\
\hline Rússia & 1,05 & 4,20 & 1,10 & 4,51 & 1,65 & 1,19 & 1,07 & 1,24 & 1,05 \\
\hline $\begin{array}{c}\text { África do } \\
\text { Sul }\end{array}$ & 0,73 & 4,37 & 0,79 & 4,47 & 0,99 & 1,00 & 1,12 & 0,95 & 0,93 \\
\hline Turquia & 0,92 & 4,45 & 0,94 & 4,39 & 1,38 & 1,00 & 1,06 & 1,17 & 1,11 \\
\hline
\end{tabular}

Fonte: elaborado pelos autores a partir dos resultados da pesquisa (2018)

A primeira coluna da Tabela 1 apresenta os países selecionados. A segunda e a quarta coluna apresentam o percentual de gastos em Pesquisa e Desenvolvimento em relação ao montante do PIB de cada país nos anos selecionados. A terceira e a quinta coluna apresentam o resultado do índice de competitividades dos países para os anos selecionados (GCI). A sexta coluna é o resultado da modificação da produtividade total (MPT). A sétima coluna (MET) representa e eficiência técnica dos gastos em P\&D para os países selecionados. A oitava coluna (MT) é o resultado do índice de Malquimist para modificaçóes de tecnologia. O índice Malquimist para eficiências em escala é representado pela nona coluna (MEE), calculados com outras variaçóes de insumos e produtos. Por fim, a última coluna da tabela representa a modificação das economias de escopo (MEESC).

O único país que diminuiu os gastos relativos em P\&D entre 2012 e 2016 foi o México. A produtividade total deste país também diminuiu impulsionado principalmente 
pela redução na eficiência em escala. Porém, houve um aumento de $10 \%$ na eficiência tecnológica, mas foi suficiente para impactar na eficiência total mexicana.

Considerando a análise do Brasil, houve aumento relativo nos gastos em P\&D entre 2012 e 2016, porém o índice de competitividade caiu. Mas os dados mostram que a sua produtividade total aumentou em cerca de $61 \%$ (MPT=1,61), principalmente impulsionada por aumentos na eficiência em escala, praticamente. Apesar do Brasil apresentar o terceiro melhor índice de produtividade total do grupo selecionado, a eficiência em escala teve mais peso do que a eficiência tecnológica, por exemplo, o que pode concluir que o país tem espaço para melhorar o índice de competitividade, melhorando a eficiência tecnológica, tais como a Coreia do Sul e África do Sul que tiveram os maiores aumentos de eficiência tecnológica entre os anos pesquisados. O que se pode inferir é que a escala de pesquisa e desenvolvimento do país pode ter sido mais utilizada entre os períodos observados.

Levando em consideração somente a eficiência técnica (MET), considerando as demais dimensóes constantes, entre 2012 e 2016 somente a Rússia teve alguma alteração de eficiência relevante entre os dois períodos observados. Ou seja, a Rússia conseguiu aumentar sua eficiência técnica em $19 \%$ entre os anos analisados. Como também melhorou sua eficiência em escala, a produtividade total ficou 65\% maior em 2016, quando comparada com 2012.

Mesmo que as DMUs não melhorem sua eficiência técnica ou que náo alterem sua escala de produção, elas se tornarão mais produtivas. Assim, as mudanças nas tecnologias dos países podem ser mais visíveis, com destaque para Coreia do Sul, que conseguiu aumentar em 15\% sua eficiência tecnológica entre os anos pesquisados.

Outra fonte de varação são as escalas de produção (MEE). Quando um país reduz os gastos em $P \& D$ mas os índices de competitividade se reduzem menos que proporcionalmente, pode-se afirmar que há uma eficiência em escala nessa DMU. Observa-se que nesse caso, os países que se destacaram são Brasil e China, com ganhos em escala de mais de $40 \%$. Nesse caso, pode-se levantar a hipótese de que quando há uma redução nos gastos em $P \& D$ por um país, o efeito sobre a reduçáo na competitividade pode ser retardatário, devido as estruturas produtivas já instaladas nesses países, por exemplo.

A eficiência em escopo (MEESC), que também pode ser chamada de eficiência da diversificação surge quando, por exemplo, o custo da produção conjunta de dois bens é menor que a soma dos custos individuais de produção para cada um deles. Nesse quesito, a China se destaca com $25 \%$ de ganho de eficiência de escopo entre os períodos analisados.

Por fim, o MPT representa a produtividade total dos fatores para cada país, entre os anos pesquisados. Toma-se o caso da Indonésia, a tecnologia desse país pode ter sofrido melhorias, o que refletiu num ganho de produtividade tecnológica de $12 \%$ mas houve perdas de eficiência em escala (12\%) e em economia de escopo (13\%), o que levou a uma perda de $14 \%$ na produtividade total, entre os anos pesquisados.

A China se destaca por ser o país que mais obteve melhorias na produtividade total (78\%), impulsionado principalmente por economias de escala e de escopo, nos anos pesquisados, conforme comparação feita com a Coreia do Sul. A Rússia também 
merece destaque por apresentar relevante mudança na produtividade total (65\%) mas diferentemente da China, a produtividade total foi baseada na eficiência técnica e de escala.

Considerando a análise da Índia e da Indonésia, os ganhos em competitividade não estão eficientes já que entre os períodos analisados, a Índia quase que dobrou os gastos relativos em $\mathrm{P} \& \mathrm{D}$, mas não houve grandes aumentos no índice de competitividade. Já a Indonésia, quase que manteve o percentual relativo dos gastos e apresentou uma melhora quase que de mesma magnitude do crescimento da Índia. Essa análise evidencia que não necessariamente os gastos em P\&D aumentam o índice de competitividade. Essa análise também é válida para a eficiência total (MPT) onde países como a África do Sul teve aumento nos gastos relativos em $\mathrm{P} \& \mathrm{D}$, mas não teve aumento na eficiência total desses gastos para aumentos de competitividade.

Mesmo com a separaçáo de comportamento econômico entre os BRICS e os MIST, apresentados por Bertão e Costa (2012), aqui não se encontra evidência que faça a necessidade de fazer uma separação dos países analisados em tais grupos. Apesar de encontrar alguma semelhança com relação aos gastos em $\mathrm{P} \& \mathrm{D}$ entre alguns países, os resultados se apresentaram bem díspares das classificaçóes encontradas no referencial teórico, evidenciando que, mesmo em países próximos, não há uma regularidade nos ambientes competitivos. A eficiência dos gastos em $P \& D$ para ganhos de competitividade não apresentou nenhum padrão de comportamento ou tendência entre os países analisados.

É válido ressaltar que as variaçôes de produtividade são diferentes para cada DMU, bem como os fatores que formam essas variaçóes. Isso decorre do fato de que cada DMU está operando com características de escala e de escopo distintas, além, é claro, de possuir níveis diferentes de eficiência técnica. Isto quer dizer que, as características tais como tamanho do mercado consumidor, políticas econômicas internacionais, produtividade do trabalho, níveis de escolaridade, ambiente político-institucional, entre outras, também avaliados no GCI, podem ter mais peso na eficiência do índice de competitividade do que os gastos em P\&D.

Por fim, os resultados destacados aqui são o caso do México, que reduziu os gastos relativos em $\mathrm{P} \& \mathrm{D}$, e perdeu competitividade entre os anos analisados, evidenciando que seus gastos precisam ser melhor direcionados, e permitindo até suspeitar de uma correlaçáo direta entre aumento de gastos em P\&D e aumento da competitividade. Por outro lado, aumentar gastos em P\&D não necessariamente pode trazer aumentos de competitividade, como nos casos da Índia, Indonésia e África do Sul, já que o índice de competitividade não acompanhou o aumento relativo dos gastos entre os anos analisados. Diante disso, pode-se concluir que não há um padrão entre os países que determinam que aumento dos gastos em $\mathrm{P} \& \mathrm{D}$ são eficientes para ganhos de competitividade, cada país necessita de refinamentos nas análises para entender melhor quais aspectos trazem mais eficiências para tal fim.

\section{Conclusóes}

O objetivo do trabalho foi calcular a eficiência dos gastos em Pesquisa e Desenvolvimento para o ganho de competitividade internacional de países selecionados tais como Brasil, Îndia, China, Rússia, África do Sul, Indonésia, Coreia do Sul, Turquia 
e México. Esse agrupamento forma um conjunto de países emergentes que possuem características econômicas próximas e permitem comparaçóes entre seus resultados.

Para isso, foram utilizados dados sobre o percentual de gastos em P\&D no PIB dos países para os anos de 2012 e 2016. Como procedimento metodológico utilizou-se Análise Envoltória de Dados, e o cálculo foi feito com as informaçôes dos anos de 2012 e 2016, por considerar que este é um intervalo mínimo para que se possa detectar indícios de mudança estrutural dos gastos em P\&D dos países.

Com exceção da Indonésia, todos os países analisados apresentaram uma estabilização quanto ao gasto de P\&D relativo ao PIB após 2008, com destaque para a China e Coreia do Sul como os países que mais dispendem recursos em P\&D com relação ao PIB. Apesar de a Coreia do Sul ser o país que mais gasta em P\&D durante os anos analisados, a China aparece como o país que gasta mais eficientemente em $P \& D$ para ganhos de competitividade, impulsionado principalmente por ganhos em escala e escopo. O México foi o único país da amostra que diminuiu seus gastos relativos em P\&D, apresentando eficiência tecnológica entre os anos analisados mas apresentou também queda de produtividade total dos fatores, evidenciando que gastar menos não necessariamente se resulta em melhorias de eficiência. $\mathrm{O}$ contrário também pode ser observado pelo Brasil, onde houve aumento dos gastos relativos em P\&D mas não houve ganhos de competitividade, ou seja, o gasto em $\mathrm{P} \& \mathrm{D}$ não foi eficiente. Por outro lado, a Índia foi o país que mais perdeu eficiência total entre os países. A perda de eficiência total foi de $56 \%$ entre os anos pesquisados. Entre os países da amostra, Índia, Indonésia, México e África do Sul perderam eficiência total dos gastos para ganhos de competitividade. Não houve perda de eficiência técnica e tecnológica em nenhum dos países pesquisados, mas houve perda de eficiência em escala na Índia, Indonésia, Coreia do Sul, México e África do Sul.

Por serem considerados países emergentes e possuírem características econômicas semelhantes, esperava-se que as eficiências dos gastos em $\mathrm{P} \& \mathrm{D}$ para ganhos de competitividade fossem também semelhantes. $\mathrm{O}$ fato é que mesmo nos países da amostra, há grandes diferenças de eficiência, que podem ser causados por diversos fatores e não somente os gastos em P\&D. Quase a metade dos países da amostra apresentou redução na eficiência total dos gastos em P\&D para ganhos de competitividade.

O trabalho apresenta importante relevância acadêmica pois dá indícios sobre a eficiência ou ineficiência dos gastos de $\mathrm{P} \& \mathrm{D}$ para ganhos de competitividade, principalmente por comparar seus resultados com países próximos. Isso permite instigar os formuladores de políticas públicas para a discussão sobre melhorar a eficiência dos gastos em $\mathrm{P} \& \mathrm{D}$, uma vez que é indiscutível, de acordo com a literatura apresentada, que países necessitem investir em pesquisa e desenvolvimento para se inserirem no comércio internacional. Evidências como encontradas na Índia podem servir de alerta para que busquem alternativas que melhorem a eficiência dos gastos em P\&D, ou seja, que os gastos em P\&D sejam direcionados a projetos que de fato tragam retorno econômico e de produtividade para o país.

$\mathrm{O}$ trabalho calculou os indicadores de eficiência dos gastos em $\mathrm{P} \& \mathrm{D}$ para o índice de competitividade. Porém, esse cálculo não permite inferir estatisticamente relaçóes de causalidade ou de correlaçóes entre essas duas variáveis. Diante disso, para trabalhos futuros, sugere-se que a análise seja continuada com outras metodologias, tais como 
análises econométricas, a fim de encontrar o impacto dos gastos em P\&D para ganhos de competitividade. Sugere-se também ampliar o número da amostra bem como o recorte temporal a fim de encontrar características que possam também impactar na competitividade dos países. Por fim, variáveis importantes como total de exportaçôes, qualidade do ambiente institucional e demais variáveis analisadas pelo Global Competitiveness Index podem ser inseridas na análise a fim de torná-la mais robusta.

\section{Referências}

ARAÚJO, W. C. O.; SILVA, E. L.; RADOS, G. J. V. Inovaçáo, competitividade e informação: breves reflexões. Perspectivas em Gestáo \& Conhecimento, João Pessoa, v. 7, n. 2, p. 98-121, jul./dez. 2017.

ARBACHE, J. Competitividade internacional e políticas públicas. International Centre for Trade and Sustainable Development. 2013. Disponível em: <https://www.ictsd. org/bridges-news/pontes/news/competitividade-internacional-e-pol\%C3\%ADticasp\%C3\%BAblicas>. Acesso em: 28 out. 2018.

ARBIX, G. et al. Inovaçáo: estratégia de sete países. Brasília, DF: ABDI, 2010.

BAUMANN, R. As Economias Emergentes e o Cenário Internacional. Instituto de Pesquisa Econômica Aplicada - IPEA: Brasília, 2016.

BERTÃO, N. I.; COSTA, A. C. Com BRICs em baixa, MIST surge como novo oásis econômico. Revista Veja. Disponível em: < https://veja.abril.com.br/economia/com-bricsem-baixa-mist-surge-como-novo-oasis-economico/>. Acesso em: 04 nov. 2018.

CARVALHO, L. C.; SERIO, L. C. D.; VASCONCELLOS, M. A. Competitividade das naçôes: análise da métrica utilizada pelo world economic forum. $\boldsymbol{R A E}$, São Paulo, v. 52, n. 4, jul./ago. 2012.

CAVALCANTI, M. F. R. et al. Reflexóes sobre Carreiras nos BRICs: Histórico e Perspectivas em Gestão de Carreiras no Brasil, Rússia, Índia e China. In: Encontro de Gestão de Pessoas e Relação de Trabalho. 3., 2011. João Pessoa, 2011.

CHANG, Ha-Joon. The political economy of industrial policy in Korea. Cambridge Journal of Economics, v. 17, n. 2, p. 131-157, 1993.

COSTA, K. F.; MENEZES, H.; FRANZONI, M. Inovação e desenvolvimento: a importância das relaçôes internacionais. Revista de Relaçóes Internacionais da UFGD, Dourados, v.5, n. 9, jan./jun., 2016.

DELAMOLLE, D. Competitividade Internacional, Ciência e Tecnologia.

Desenvolvimento em questáo, Editora Unijuí, ano 3, n. 5, jan./jun., 2005. 
FEDATO, G. A. L.; PIRES, V. M.; TREZ, G. O Futuro da Pesquisa em Implementação de Estratégia no Contexto do BRICS. Brazilian Business Review, v. 14, n. 3, p. 288303, fev. 2017.

FERNANDES, L. et al. Policy Brief: o Desenvolvimento Desigual na Era do Conhecimento: A Evolução da Participação dos BRICS no Registro de Propriedade Intelectual e Investimentos em P\&D. Núcleo de Sistemas de Inovação e Governança do Desenvolvimento. 2012.

FERREIRA, L.; CARVALHO, C. O. Investimento em tecnologia: uma análise comparativa entre os países do BRICS. In: Simpósio de Excelência em Gestão e Tecnologia. 7., 2010. Resende, RJ, 2010.

FLÁVIO VILELA VIEIRA, F. V.; VERÍSSIMO, M. P. Crescimento econômico em economias emergentes selecionadas: Brasil, Rússia, Índia, China (BRIC) e África do Sul. Economia e Sociedade, Campinas, v. 18, n. 3, p. 513-546, dez. 2009.

GAMEIRO, M. B. P.; GAMEIRO, A. H. Globalização da P\&D: impactos nos países em desenvolvimento. In: Congresso do Saber. 44., 2006. Fortaleza, 2006.

INSTITUTO DE PESQUISA ECONÔMICA APLICADA - IPEA. Conheça os BRICS. In: Fórum acadêmico. 6., 2014, Rio de Janeiro, 2014. Disponível em: < http:// www.ipea.gov.br/forumbrics/pt-BR/conheca-os-brics.html>. Acesso em 05 Nov. 2018.

INSTITUTO DE PESQUISA ECONOMICA APLICADA - IPEA. Rússia, Índia e China: comércio exterior e investimento direto externo. Comunicados do Ipea, n. 43, 14 abr. 2010. Disponível em: http://www.ipea.gov.br/portal/images/stories/PDFs/ comunicado/100413_comunicadoipea43.pdf. Acesso em: 30 out 2018.

MARTINS, M. W. L. et al. Evidenciaçáo dos investimentos em P\&D e os reflexos no desempenho organizacional. In: encontro nacional de engenharia de produção, 36. 2016. João Pessoa, PB, 2016.

MINISTÉRIO DAS RELAÇÕES EXTERIORES. Informação sobre o BRICS.

Disponível em: http://brics6. itamaraty.gov.br/pt_br/sobre-o-brics/informacao-sobre-obrics. Acesso em: 05 nov. 2018.

NAKANO, Y. Globalização, competitividade e novas regras do comercio mundial.

Revista de economia e política, v. 14, n. 4. Out./dez., 1994.

NELSON, R. R. As fontes do crescimento econômico. Campinas: Editora da Unicamp, 2006.

OECD. Industrial competitiveness: benchmarking business environment in the global economy. OECD: Paris, 1996. 
PASTOR, R. et al. Algoritmos de busca Tabu para um problema de balanceamento de linha de montagem multi-produto e multi-objetivo industrial, com redução da dispersão da tarefa. Jornal da Sociedade de Pesquisa Operacional, Birmingham (Inglaterra), v. 53, n. 12, p. 1317-1323, 2002.

PIMENTA, G. F. Globalização e países emergentes: uma perspectiva das cidades globais. Conjuntura Internacional, Belo Horizonte, v. 10, n. 1, p. 51 - 62, 1 sem. 2013.

PORTUGUESE.PEOPLE.CN. BRICS lidera inovação em ciência e tecnologia entre os países em desenvolvimento. portuguese.people.cn. 2017. Disponível em: < http:// portuguese.people.com.cn/n3/2017/0830/c309806-9262201.html>. Acesso em 29 out. 2018.

REIS-CARDOSO, H. Internacionalização de empresas em Estados emergentes: um reflexo de suas condiçóes institucionais. Fronteira, Belo Horizonte, v. 9, n. 18, p. 67 - 84, 267 o sem. 2010.

ROSSI, C. Para Fórum Econômico, Brasil está longe da fronteira da competitividade.

Folha de Sáo Paulo. 2018. Disponível em: https:/www1.folha.uol.com.br/ mercado/2018/10/para-forum-economico-brasil-esta-longe-da-fronteira-dacompetitividade.shtml. Acesso em: 28 out. 2018.

SCHMIDT FILHO, R.; LIMA, B. G. C. C. Padrão de especialização e competitividade internacional dos BRICS: 1985-2012. Revista Economia Ensaios, Uberlândia, MG. v. 28, n. 2, p. 43-76, Jan./Jun. 2014.

SILVA, C. L. Fatores determinantes da competitividade internacional da indústria de papel de imprimir e escrever sob a ótica da cadeia de valor. Revista Brasileira de Gestáo de Negócios, ano 6, número 14, abr. 2004.

SOARES, R. B.; SANTOS, E. H. BRICS: compreender o contexto "BRICS" e qual sua importância para o Brasil. In: ENANGRAD. 28., 2017. Brasília, 2017.

TAVARES, M. C.; AFONSO, T. Cluster: competitividade internacional, inovação. Rev. Gestáo \& Tecnologia. Pedro Leopoldo, MG, v. 1, n. 1, p. 1-13. 2002. Disponível em: < http://revistagt.fpl.edu.br/get/article/view/108>. Acesso em: 01 nov. 2018.

VIEIRA, F. V. VERÍSSIMO, M. P. Crescimento econômico em economias emergentes selecionadas: Brasil, Rússia, Índia, China (BRIC) e África do Sul. Economia e Sociedade, Campinas, v. 18, n. 3, p. 513-546, dez. 2009. 